\title{
Design of a Charge-Average Type SC DC-DC Converter for Cellular Phones
}

\author{
Kei Eguchi* Member \\ Fumio Ueno** Member \\ Hongbing $\mathrm{Zhu}^{* * *}$ Member \\ Toru Tabata* Non-member \\ Takahiro Inoue ${ }^{* * * *}$ Member
}

\begin{abstract}
A charge-average type DC-DC converter for cellular phones is proposed in this paper. The converter is designed by using switched-capacitor (SC) techniques. In the proposed power converter, the DC-DC conversion is performed by iterating the following processes. Firstly, an input voltage $V_{i n}$ is charged in capacitors which are connected in series. In this timing, an output voltage is taken out from arbitrary terminals of the capacitors. Next, the electric charges are equalized by connecting the capacitors in parallel. Therefore, different from conventional converters such as a series-parallel type converter and a Dickson-type converter, the proposed converter can provide stepped-down and stepped-up voltages which are expressed by $(Q / P) \times V_{\text {in }}$ $(P \in\{1,2, \ldots, N\}$ and $Q \in\{1,2, \ldots, N\})$. Furthermore, the hardware cost for the proposed converter is smaller than that for the conventional SC power converters such as a ring-type converter and a series-parallel type converter. Concerning 3-stage power converters, SPICE simulations are performed to confirm the validity of the circuit design. For the input voltage $3.6 \mathrm{~V}$, the power efficiency of the proposed circuit is about $90 \%$ in the output current about $300 \mathrm{~mA}$.
\end{abstract}

Keywords: DC-DC converters, switched-capacitor circuits, bootstrap circuits, cellular phones, discrete-time circuits

\section{Introduction}

In the development of mobile equipments, a power converter is one of the most important building blocks. For the realization of the power converters, two major approaches have been studied : a power converter using inductors and an inductor-less power transformer using switched-capacitor (SC) techniques ${ }^{(1) \sim(15)}$. $\mathrm{Al}-$ though the converters using inductors can realize high efficiency of power conversion, they have the following disadvantages: the magnetic elements such as inductors cause the possibility of faulty operation for the neighboring circuits and the increase of volume and weight. In the design of the converters for mobile equipments such as cellular phones, thin circuit composition and lightweight are desirable. For this reason, several attempts have already been made for the realization of the SC power transformers. For example, Mak et al. realized a series-parallel type power converter ${ }^{(3)}$, Dickson proposed a stepped-up power converter ${ }^{(5)}$, and Hara et al.

\footnotetext{
* Kumamoto National College of Technology

2659-2, Suya, Nishigoshi, Kikuchi, Kumamoto, Japan 8611102

** Sojo University

1-2-70, Nishihara, Kumamoto, Japan 862-0929

*** Hiroshima Kokusai Gakuin University

6-20-1, Nakano, Akiku, Hiroshima, Japan 739-0321

**** Kumamoto University

2-40-1, Kurokami, Kumamoto, Japan 860-8555
}

proposed a ring-type type DC-DC converter ${ }^{(13)}$. The types of voltage-conversion depend on the structure of the SC power converters. In cellular phones, the DC voltages such as $2.3 \mathrm{~V}$ and $5.0 \mathrm{~V}$ are required for CPU's and diode-lamps, respectively. Therefore the SC DC-DC converters which can generate a $2 / 3$ stepped-down voltage or a $3 / 2$ stepped-up voltage are desirable, because the typical voltage of the lithium-ion battery is about $3.6 \mathrm{~V}$.

In this paper, a charge-average type DC-DC converter for cellular phones is proposed. The converter is designed by using switched-capacitor (SC) techniques. In the proposed power converter, the DC-DC conversion is performed by iterating the following processes. Firstly, an input voltage $V_{i n}$ is charged in capacitors which are connected in series. In this timing, an output voltage is taken out from arbitrary terminals of the capacitors. Next, the electric charges are equalized by connecting the capacitors in parallel. Therefore, different from conventional converters such as a seriesparallel type converter and a Dickson-type converter, the proposed converter can provide stepped-down and stepped-up voltages which are expressed by $(Q / P) \times V_{\text {in }}$ $(P \in\{1,2, \ldots, N\}$ and $Q \in\{1,2, \ldots, N\})$. Furthermore, the hardware cost for the proposed converter is smaller than that for the conventional SC power converters such as a ring-type converter and a series-parallel type converter. Concerning 3-stage power converters, 


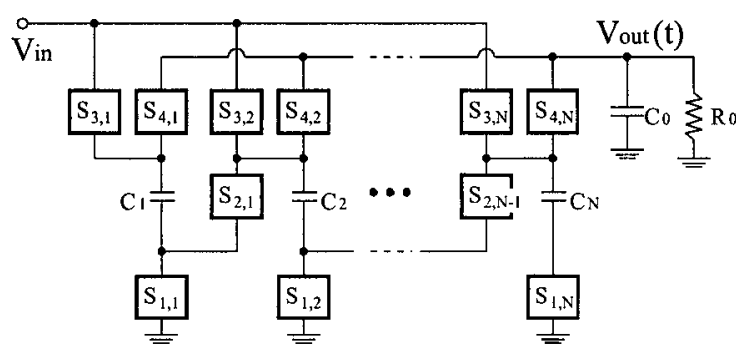

Step-down process

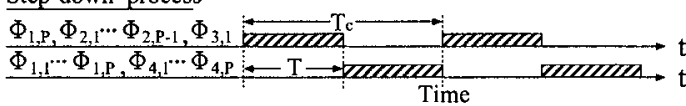

Step-up process

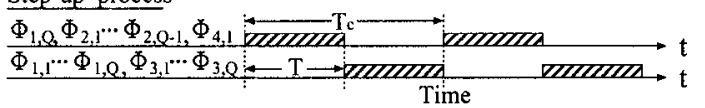

Fig. 1. Series-parallel type power converter.

SPICE ${ }^{(16)}$ simulations are performed to confirm the validity of the circuit design.

\section{Circuit Structure}

2.1 Series-Parallel Type DC-DC Converter Figure 1 shows a series-parallel type power converter (3) (4). The conventional converter consists of $4 N-1$ power switches and $N+1$ capacitors. By controlling the power-switches $S_{i, j}((i=1, \ldots, 4)$ and $(j=$ $1,2, \ldots, N)$ ), the circuit converts a voltage to other by means of changing the connections of capacitors. The power-switches $S_{i, j}$ are driven by non-overlapped 2-phase pulses $\Phi_{i, j}$.

In the step-down process, firstly, the capacitors $C_{1}, \ldots, C_{P}$ are connected in series via $S_{2, j}$. In this timing, a charged-voltage of each capacitor becomes $V_{i n} / P$ since $C_{1}, \ldots, C_{P}$ are charged by the input voltage $V_{i n}$. Next, $C_{1}, \ldots, C_{P}$ are connected in parallel via $S_{4, j}$. In this timing, the output voltage $V_{i n} / P$ is obtained. The step-down conversion is achieved by iterating these operations.

In the step-up process, firstly, the capacitors $C_{1}, \ldots$, $C_{Q}$ are connected in parallel via $S_{3, j}$. In this timing, a charged-voltage of each capacitor becomes $V_{i n}$ since $C_{1}, \ldots, C_{Q}$ are charged by $V_{i n}$. Next, these capacitors are connected in series via $S_{2, j}$. In this timing, the output voltage $Q V_{i n}$ is obtained via $S_{4,1}$. The step-up conversion is achieved by iterating these operations.

When the output current is 0 and the voltage-drop caused by power-switches is free, the output voltage $V_{\text {out }}(t)$ is given by

$$
V_{\text {out }}(t)= \begin{cases}(1 / P) V_{\text {in }}, & \text { when } \\ Q V_{\text {in }}, & \text { when down }\end{cases}
$$

where $P \in\{1,2, \ldots, N\}$ and $Q \in\{1,2, \ldots, N\}$. As Eq.(1) shows, the series-parallel type power converter cannot provide $2 / 3$ stepped-down voltage or $3 / 2$ stepped-up voltage.

2.2 Dickson Type DC-DC Converter Figure 2 shows a Dickson-type power converter ${ }^{(5) \sim(12)}$. The conventional converter consists of $N+1$ power switches

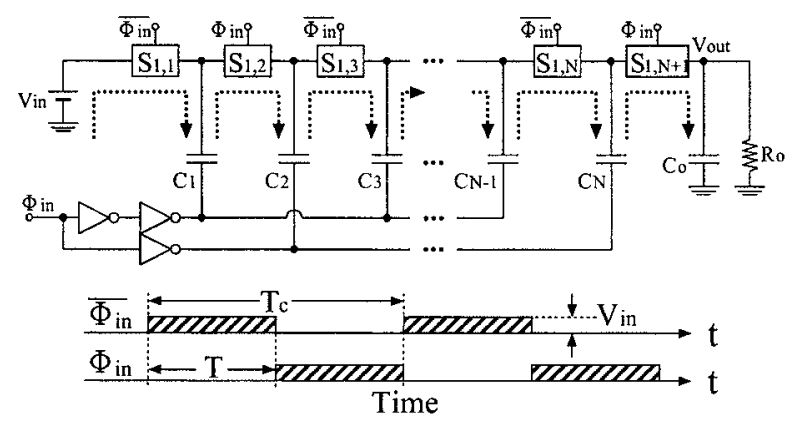

Fig. 2. Dickson-type power converter.
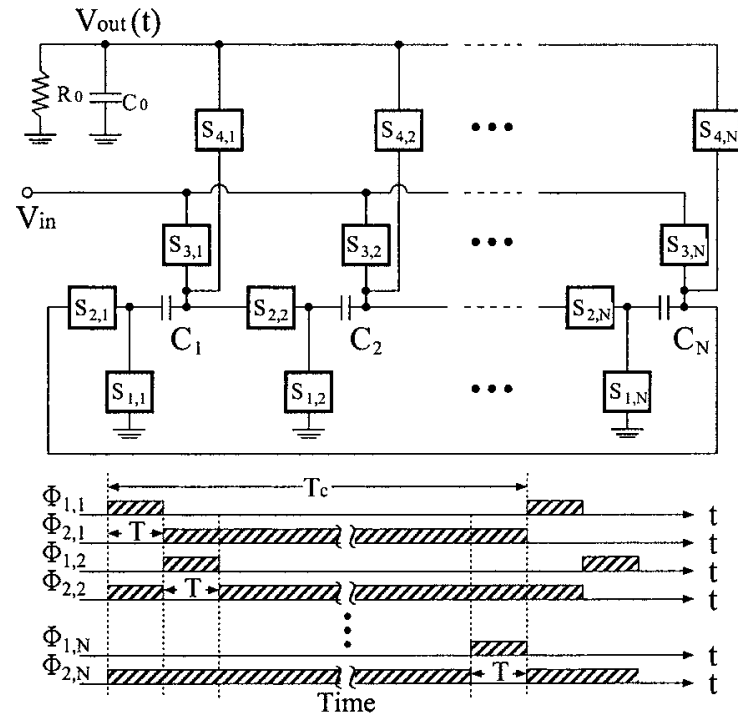

Fig. 3. Ring-type power converter.

and $N+1$ capacitors. The power-switches $S_{1, j}(j=$ $1,2, \ldots, N+1)$ are also driven by non-overlapped 2 phase pulses $\Phi_{i n}$ and $\overline{\Phi_{i n}}$. When $\Phi_{i n}$ is Low, 2 adjacent capacitors are connected in parallel via $S_{1, m}$ $(m=1,3,5, \ldots)$. In this timing, the voltage of $\Phi_{i n}$ is added to the voltages of $C_{n}(n=2,4,6, \ldots)$. On the other hand, when $\Phi_{i n}$ is $H i g h, 2$ adjacent capacitors are connected in parallel via $S_{1, n}(n=2,4,6, \ldots)$. In this timing, the voltage of $\Phi_{i n}$ is added to the voltages of $C_{m}$ $(m=1,3,5, \ldots)$. The step-up conversion is achieved by iterating these operations.

When the output current is 0 and the voltage-drop caused by power-switches is free, the output voltage $V_{\text {out }}(t)$ is given by

$$
V_{\text {out }}(t)=N V_{\text {in }} \ldots \ldots \ldots \ldots \ldots \ldots \ldots \ldots \ldots
$$

As Eq.(2) shows, the Dickson-type power converter provides a stepped-up voltage only.

2.3 Ring Type DC-DC Converter Figure 3 shows a ring-type power converter ${ }^{(13) \sim(15)}$. The conventional converter consists of $4 N$ power switches and $N+1$ capacitors. In Fig. 3 , the clock pulses for $S_{1, j}$ are non-overlapped $N$-phase pulses $\Phi_{i, j}((i=1, \ldots, 4)$ and $(j=1,2, \ldots, N))$, and the clock pulses for $S_{2, j}$ are set to the inverted pulses of $\Phi_{1, j}$. The switches $S_{3, j}$ and $S_{4, j}$ are driven by the clock pulses obtained by shifting the clock-pulses $\Phi_{1, j}$ cyclically.

When the output current is 0 and the voltage-drop 


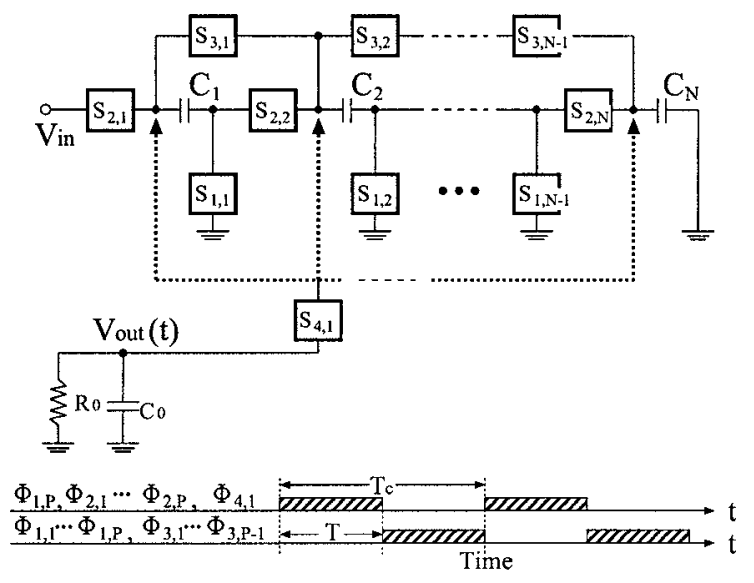

(a) Step-down type.
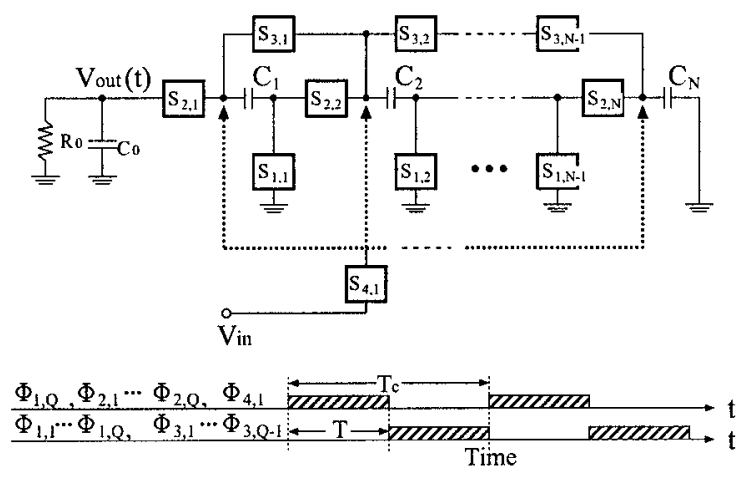

(b) Step-up type.

Fig. 4. Proposed converter.

caused by power-switches is free, the output voltage $V_{\text {out }}(t)$ is given by

$$
V_{\text {out }}(t)=\frac{Q}{P} V_{\text {in }},
$$

where $P$ and $Q \in\{1,2, \ldots, N\}$ denote the number of the capacitors connected to an input terminal and an output terminal, respectively. The parameters $P$ and $Q$ are determined by the timing of the clock pulses for $S_{3, j}$ and $S_{4, j}$, respectively. Different from the series-parallel type converter and the Dickson-type converter, the output voltage of the ring-type converter is always obtained irrespective of the states of the clock pulses.

As Figs. $1 \sim 3$ show, the hardware-cost for the ringtype power converter is larger than that for the seriesparallel type and the Dickson-type. Furthermore, the control of the power-switches is complex since the ringtype power converter requires $N$-phase clock pulses. However, it can generate various types of output voltages, and the ripple noise of the output voltage is small.

2.4 Proposed Power Converter Figure 4 shows the proposed charge-average type power converter. The proposed converter consists of $3 N-1$ power switches and $N+1$ capacitors. The power-switches $S_{i, j}$ are driven by non-overlapped 2-phase pulses $\Phi_{i, j}$. As for the point that step-down type differs from step-up type, the input terminal and the output terminal are only changed.

Figure 5 shows instantaneous equivalent circuits when step-down process. In the case of State $-I$, the capaci-

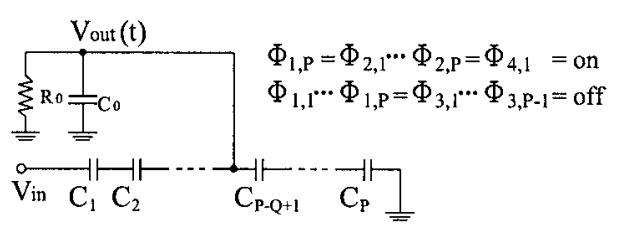

(a) State-I.

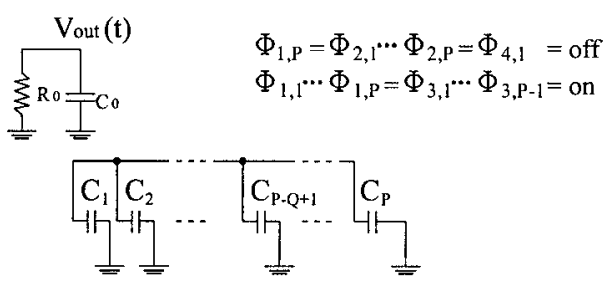

(b) State-II.

Fig. 5. Instantaneous equivalent circuits when step-down process.

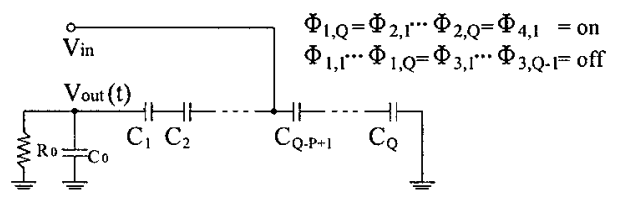

(a) State-I.

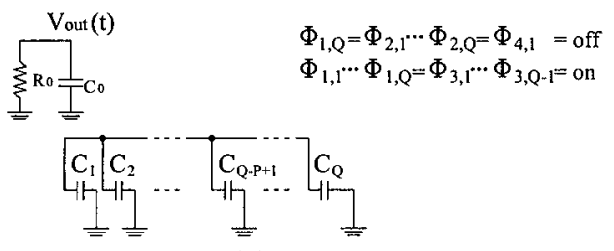

(b) State-II.

Fig. 6. Instantaneous equivalent circuits when step-up process.

tors $C_{1}, \ldots, C_{P}$ and the input voltage $V_{i n}$ are connected in series via $S_{2, j}$. In this timing, a stepped-down voltage is taken out from the left-terminal of $C_{P-Q+1}$ via $S_{4,1}^{\dagger}$ (see in Fig.4 (a)). Hence, the electric charges in the capacitors from $C_{P-Q+1}$ to $C_{P}$ are consumed by the output load $R_{o}$. However, in the case of State - II, the electric charges in $C_{1}, \ldots, C_{P}$ are averaged by connecting these capacitors in parallel. The step-down conversion is performed by iterating these processes.

Figure 6 shows instantaneous equivalent circuits when step-up process. In the case of State - I, the capacitors $C_{1}, \ldots, C_{Q}$ are connected in series via $S_{2, j}$, and the input voltage is given to the left-terminal of $C_{Q-P+1}$ via $S_{4,1}$ (see in Fig.4 (b)). In this timing, an output voltage $(Q / P) V_{\text {in }}$ is obtained since $C_{1}, \ldots, C_{Q}$ are connected to an output terminal. On the other hand, in the case of State - II, the electric charges in $C_{1}, \ldots, C_{Q}$ are averaged by connecting these capacitors in parallel. The step-up conversion is performed by iterating these processes.

When the output current is 0 and the voltage-drop caused by power-switches is free, the output voltage $V_{\text {out }}(t)$ is given by

$$
V_{\text {out }}(t)=\frac{Q}{P} V_{\text {in }}
$$

$\dagger$ In the case of $1 / P$ step-down conversion, the power-switch $S_{4,1}$ is shorted. 
Table 1. Types of power conversions.

\begin{tabular}{|l||c|c|}
\hline & $\begin{array}{c}\text { Type of } \\
\text { conversion }\end{array}$ & $\begin{array}{c}\text { Step of } \\
\text { conversion }\end{array}$ \\
\hline \hline Series-parallel type & $\begin{array}{c}\text { Step-up } \\
\text { and } \\
\text { step-down }\end{array}$ & $\begin{array}{c}(1 / P) V_{i n} \\
\text { or } \\
(Q) V_{i n}\end{array}$ \\
\hline Dickson type & Step-up & $(N) V_{i n}$ \\
\hline Ring type & $\begin{array}{c}\text { Step-up } \\
\text { and } \\
\text { step-down }\end{array}$ & $(Q / P) V_{i n}$ \\
\hline Proposed-I & $\begin{array}{c}\text { Step-up } \\
\text { or } \\
\text { step-down }\end{array}$ & $(Q / P) V_{i n}$ \\
\hline \multicolumn{2}{|c|}{$(P \in\{1,2, \ldots, N\}, Q \in\{1,2, \ldots, N\})$}
\end{tabular}

Table 2. Material costs for power converters.

\begin{tabular}{|l||c|c|}
\hline & $\begin{array}{c}\text { Power } \\
\text { switch }\end{array}$ & Capacitor \\
\hline \hline Series-parallel type converter & $4 N-1$ & $N+1$ \\
\hline Dickson type converter & $N+1$ & $N+1$ \\
\hline Ring type converter & $4 N$ & $N+1$ \\
\hline Proposed converter & $3 N-1$ & $N+1$ \\
\hline \multicolumn{2}{|c|}{$(N=1,2, \ldots)$}
\end{tabular}

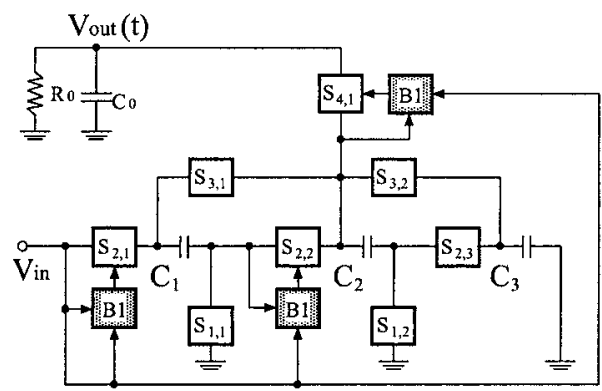

(a) Step-down type.

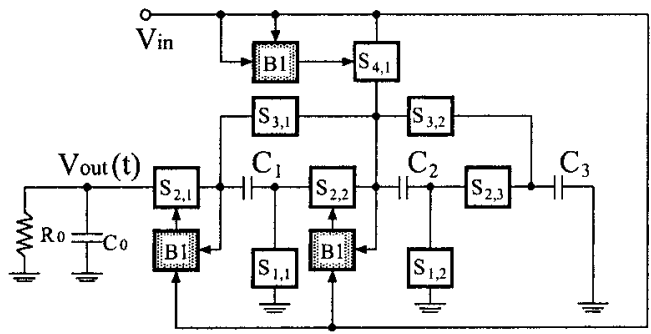

(b) Step-up type.

Fig. 7. 3-stage charge-average type power converters.

Table 1 shows the types of power conversions. As Table 1 shows, the proposed converter can provide steppeddown or stepped-up voltages such as $(2 / 3) V_{i n},(3 / 2) V_{i n}$, and so on. Furthermore, different from the ring-type converter, the control of the power-switches for the proposed converter is simple since the switches are driven by using 2-phase clock pulses. Table 2 shows the material cost for the power converters. As Table 2 shows, the charge-average type power converter can realize small hardware-cost and simple control of the power-switches.

\section{Simulation}

To confirm the validity of the circuit design, SPICE simulations were performed concerning 3-stage power converters shown in Fig. $7^{\dagger}$. The power converter shown in Fig.7 (a) can provide $(1 / 2) V_{i n},(1 / 3) V_{i n}$, and

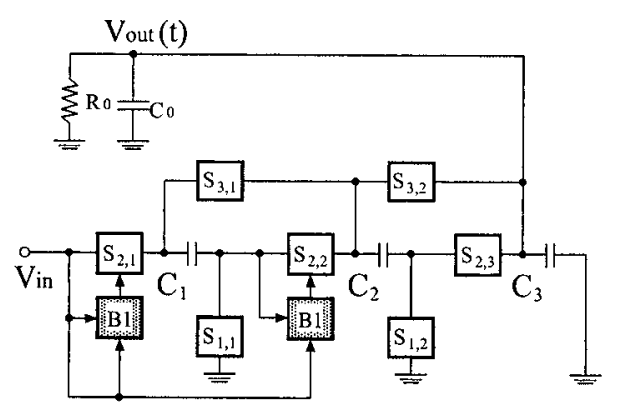

Fig. 8. 3-stage charge-average type power converter which provides $1 / 3$ stepped-down voltage.

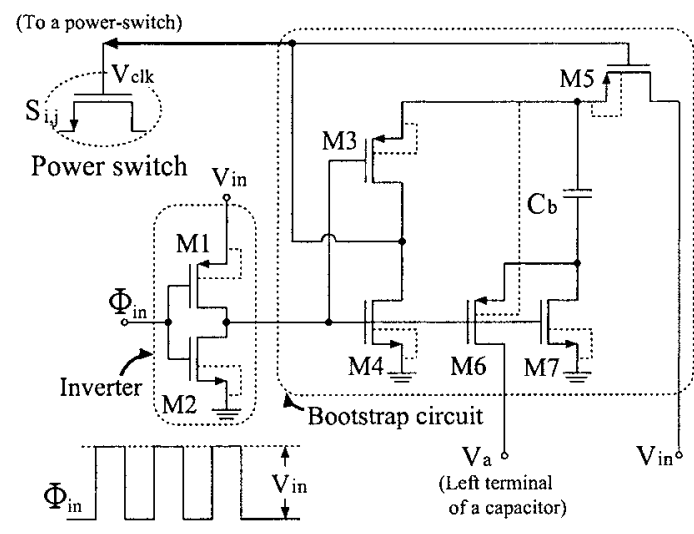

Fig. 9. An example of bootstrap circuits (B1).

$(2 / 3) V_{i n}$. The converter consists of 8 power-switches and 4 capacitors. However, the converter for specific uses which performs $1 / 3$ stepped-down conversion can be redesigned as shown in Fig.8. The converter of Fig.8 can be constructed with 7 power-switches and 4 capacitors. In the simulated converters, to avoid the threshold voltage drop caused by power-switches, bootstrap circuits shown in Fig.9 were attached to the power-switches.

Figure 10 shows the transient characteristics of the simulated converters. The SPICE simulations were performed under the conditions that the input voltage $V_{\text {in }}=3.6 \mathrm{~V}^{\dagger \dagger}, C_{j}=5 \mu \mathrm{F}, C_{o}=5 \mu \mathrm{F}, C_{b}=1 \mathrm{nF}$, and the on-resistance of the power-switch $R_{o n}=0.25 \Omega$. In Figs.10 (a) and (b), the output loads $R_{o}$ were set to $7 \Omega$ and $30 \Omega$, respectively. As Fig.10 shows, the values of the output voltages of the ring-type converter is larger than that of the proposed converter. However, the settling time for the proposed converter is faster than that for the ring-type converter, because the proposed circuit can be driven by 2-phase clock pulses.

Figures 11 and 12 show the power efficiency $E_{p}$ and the voltage efficiency $E_{v}{ }^{\dagger \dagger}$ of the converters, respectively. When the output load $R_{o}$ is large, the proposed converter is superior to the ring-type power converter in

$\dagger$ The simulations for the series-parallel type power converter and the Dickson-type power converter are omitted since the aim of our research is the design of the SC DC-DC converter for cellular phones. As Table 1 shows, these conventional converters cannot provide the output voltages such as $(2 / 3) V_{i n}$ and $(3 / 2) V_{i n}$.

$\dagger^{\dagger}$ In cellular phones, the typical voltage of the lithium-ion battery is about $3.6 \mathrm{~V}$.

$\dagger \dagger \dagger$ We defined the voltage efficiency $E_{v}$ as $E_{v} \triangleq V_{\text {out }}(t) / V_{\text {ideal }} \times$ $100(\%)$, where $V_{\text {ideal }}$ denotes an ideal output voltage. 


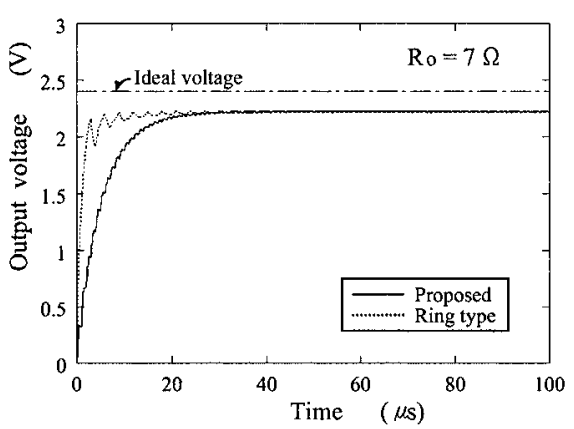

(a) $2 / 3$ step-down

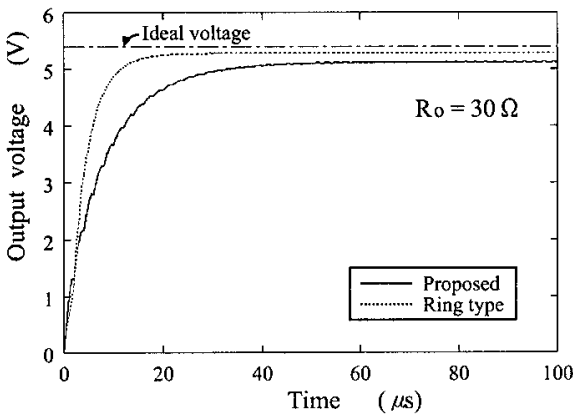

(b) $3 / 2$ step-up.

Fig. 10. Transient characteristics.

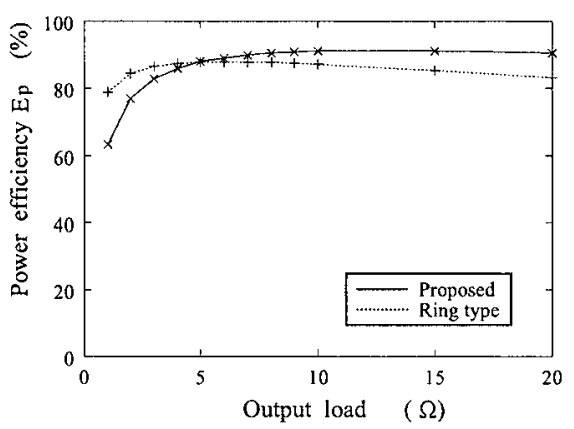

(a) $2 / 3$ step-down

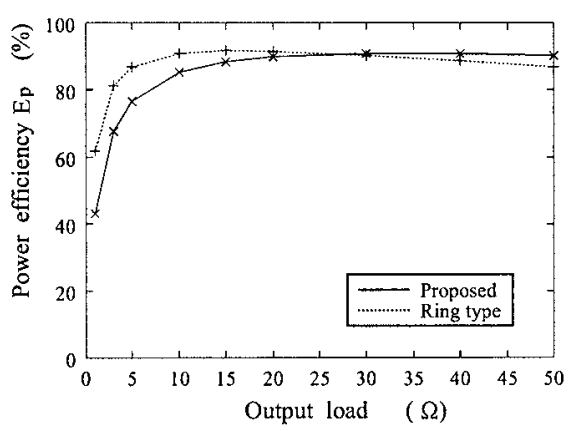

(b) $3 / 2$ step-up.

Fig. 11. Power efficiency $E_{p}$ for the simulated converters.

respect of $E_{p}$. In the case of $2 / 3$ step-down conversion, $E_{p}$ of the proposed converter is about $90 \%^{\dagger \dagger \dagger \dagger}$ in the output current about $300 \mathrm{~mA}$. On the other hand, in the case of $3 / 2$ step-up conversion, $E_{p}$ of the proposed converter is about $91 \%$ in the output current about $170 \mathrm{~mA}$.

††† The power efficiency of the proposed converter can be improved by using the power-switches with small on-resistance.

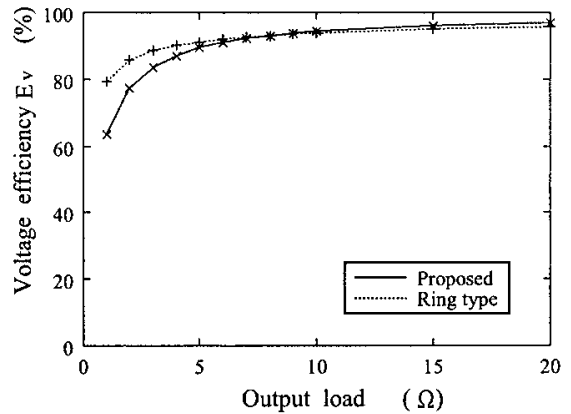

(a) $2 / 3$ step-down.

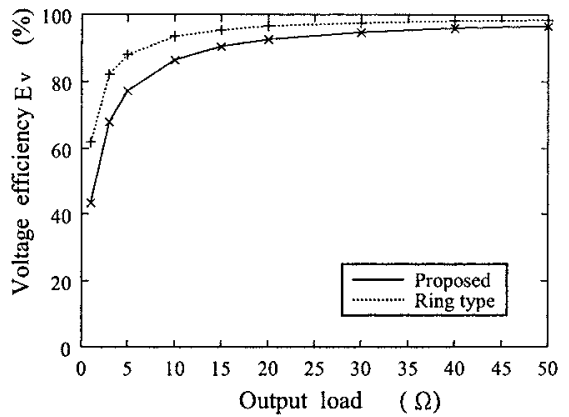

(b) $3 / 2$ step-up.

Fig. 12. Voltage efficiency $E_{v}$ for the simulated converters.

\section{Conclusion}

A charge-average type DC-DC converter for cellular phones has been proposed in this paper. The validity of the circuit design was confirmed through SPICE simulations. The simulations showed the following results.

1. Different from a series-parallel type converter and a Dickson-type converter, the proposed converter can provide various types of output voltages such as $(2 / 3) V_{i n}$, $(3 / 2) V_{i n}$, and so on. 2 . For the input voltage $3.6 \mathrm{~V}$, the power efficiency of the proposed converter is about 90 $\%$ in the output current about $300 \mathrm{~mA}$. 3. The material cost for the proposed converter is smaller than that for the conventional power converters such as a ring-type converter and a series-parallel type converter.

The further improvement of efficiency is left to the future study.

(Manuscript received May 10, 2004, revised Sep. 1, 2004)

\section{References}

(1) I. Harada, F. Ueno, T. Inoue, and I. Oota: "Characteristics analysis of Fibonacci type SC transformer", T.IEICE, Fundamentals, Vol.E75-A, No.6, pp.655-662 (1992-6)

( 2 ) I. Oota, N. Hara, and F. Ueno: "A differential type switchedcapacitor transformer", Proc. of the International Symposium on Nonlinear Theory and its Applications, Vol.2, pp.1213$1215(1997-8)$

(3) O.C. Mak and A. Ioinovici: "Inductorless switched-capacitor inverter with high power density", Symp. on Power Electronics Circuits, Vol.2, pp.1272-1278 (1994-6)

(4) N. Hara, I. Oota, S. Suzuki, and F. Ueno: "Realization and analysis of a new switched-capacitor coilless power supply for one chip IC form", Trans. of IEEJ, Vol.J81-D-I, No.2, pp.165178, (Feb. 1998) 
(5) J.F. Dickson: "On-chip high-voltage generation in NMOS integrated circuits using an improved voltage multiplier techniques", T.IEEE, Solid-State Circuits, Vol.SC-11, No.3, pp.374-378 (1976-3)

(6) T. Tanzawa and T. Tanaka: "A dynamic analysis of the Dickson charge pump circuit", T.IEEE, Solid-State Circuits, Vol.32, No.8, pp.1237-1240 (1997-8)

( 7 ) S.C.Lee and S.H.Lee: "A low-ripple switched-capacitor DCDC up converter for low-voltage applications", T.IEICE, Electron., Vol.E84-C, No.8, pp.1100-1103 (2001-8)

(8) T. Myono, A. Uemoto, S. Kawai, E. Nishibe, S. Kikuchi, T. Iijima, and H. Kobayashi: "High-efficiency charge-pump circuits with large current output for mobile equipment applications", T.IEICE, Electron., Vol.E84-C, No.10, pp.1602-1611 (2001-10)

(9) K.Min and J.Ahn: "CMOS charge pumps using cross-coupled charge transfer switches with improved voltage pumping gain and low gate-oxide stress for low-voltage memory circuits", T.IEICE, Electron., Vol.E85-C, No.1, pp.225-229 (2002-1)

(10) H. San, H. Kobayashi, T. Myono, T. Iijima, and N. Kuroiwa: "Highly-efficient low-voltage-operation charge pump circuits using bootstrapped gate transfer switches", T.IEEJ, Vol.120C, No.10, pp.1339-1345 (2000-10)

(11) J.T. Wu and K.L. Chang: "MOS charge pumps for lowvoltage operation", T.IEEE, Solid-State Circuits, Vol.33, No.4, pp.592-597 (1998-4)

(12) K. Eguchi, H. Zhu, T. Tabata, and F. Ueno: "A Dickson-type power converter with bootstrapped gate transfer switches", Proc. of the 25th International Telecommunications Energy Conference, pp.623-626 (2003-10)

(13) N. Hara, I. Oota, F. Ueno, and T. Inoue: "A new ring type set-up switched-capacitor DC-DC converter with low inrush current at start-up and low current ripple in steady state", $T$. IEEJ, Vol.J81-C-II, No.7, pp.600-612 (1998-7)

(14) N.Hara, I.Oota, I.Harada, and F.Ueno: "Programmable ring type switched-capacitor DC-DC converters", T. IEEJ, Vol.J82-C-II, No.2, pp.56-68 (1999-2)

(15) K. Eguchi, F. Ueno, T. Tabata, and H. Zhu: "A ring-type SC DC-DC converter with bootstrapped gate transfer switches", Proc. of the International Symposium on Nonlinear Theory and its Applications, pp.191-194 (2002-10)

(16) PSpice user's guide, MicroSim Corporation (1989)

Kei Eguchi (Member) received the B.E., the M.E., and the

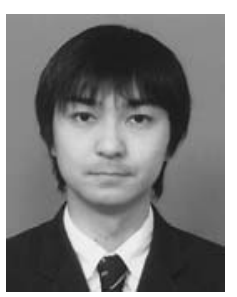
D.E. degrees from Kumamoto University, Kumamoto, Japan in 1994, 1996, and 1999, respectively. Presently he is an Associate Professor in Kumamoto National College of Technology. His research interests include nonlinear dynamical systems, intelligent circuits and systems, and low-voltage analog integrated circuits. He is a member of IEICE.

Fumio Ueno (Member) received the B.E. degree in elec-

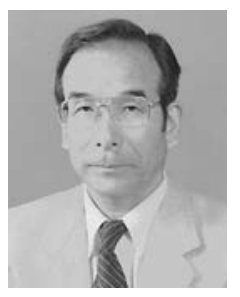
trical engineering from Kumamoto University, Kumamoto, Japan, in 1955, and M.E. degree and D.E. degree from Kyusyu University Fukuoka, Japan, in 1964, 1968 respectively. He was the faculty of Kumamoto University, where he was a Professor, Dean in 1992. Since 1994 he has been the President at Kumamoto National College of Technology, and IEICE Kyusyu Branch Chair in 1995. His main interest lies in the field of active networks. Dr. Ueno is a member of IEICE, Japan Society for Fuzzy Theory and Systems, and IEEE.
Hongbing Zhu (Member) has the B.S., the M.S. and the

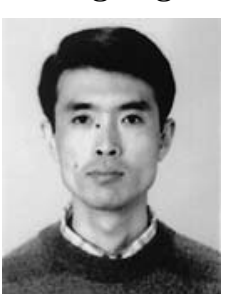
the Ph.D. degrees. He was an Assistant Professor and Lecture of Information Science \& Engineering faculty, Wuhan University of Science \& Technology, and Information Processing Center, Kumamoto University. And he worked as a visiting scholar at Kyushu Tokai University and Kumamoto University. Now, he is an Associate Professor of Hiroshima Kokusai Gakuin University. His current research interests include neural networks, non Neumann computer and high-speed processing, etc.. He is also a member of IEEE, IEICE, JNNS, IPSJ.

Toru Tabata

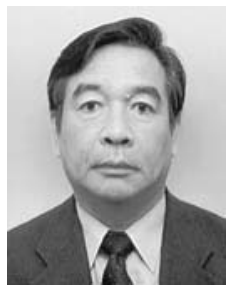

(Non-member) was born in Kumamoto, Japan in 1946. He received the B.E., the M.E., and the D.E. degree in electrical engineering from Kumamoto University, Kumamoto, Japan, in 1970, 1972, and 1999, respectively. Currently, he is a Professor of the Department of Electronic Control at Kumamoto National College of Technology. His research interests and activities include the multiple-valued computer arithmetic circuits. He is a member of IEICE

and IPS of Japan

Takahiro Inoue (Member) received the B.E. and the

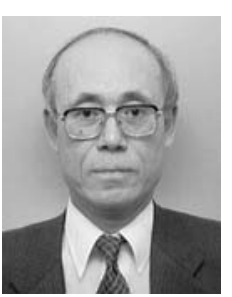
M.E. degree from Kumamoto University, Kumamoto, Japan in 1969 and 1971, respectively, and the D.E. degree from Kyushu University, Fukuoka, Japan in 1982. From 1971 to 1974 , he worked as a Research Staff at Hitachi, Ltd., Yokohama, Japan. In 1975, he joined the faculty of Kumamoto University, where he is now a Professor. Dr. Inoue's current research interests include switched-capacitor/switchedcurrent filters, continuous-time IC filters, low-power/low-voltage analog integrated circuits, and analog/digital intelligent circuits and systems. $\mathrm{He}$ is a member of the Institute of Electrical and Electronics Engineers and he served as an Associate Editor of Transactions on Fuzzy Systems during 1994-1996. He is also a member of the Japanese Neural Network Society, and the Physical Society of Japan. 